\title{
STAKEHOLDERS INVOLVEMENT IN MITIGATING DISASTER PREVALANCE FOR EFFECTIVE DISASTER MANAGEMENT
}

\author{
Saeed Al-Fazari and Narimah Kasim* \\ Department of Construction Management, Faculty of Technology Management \& Business, Universiti Tun Hussein \\ Onn Malaysia, 86400 Batu Pahat, Johor, Malaysia \\ E-mail:*narimah@uthm.edu.my
}

\begin{abstract}
A literature search showed that studies on the categorization and roles of stakeholders engaged in disaster management are still in dearth. This could not be unrelated to the global trend of natural and man-made disasters. The objective of this research is therefore to examine the role played by stakeholders in combating the incidence of disasters in our modern culture. An audit of suitable writing is the method utilized to collect fitting data. The investigation found diverse strategies of categorizing calamity administration partners in past investigate. This investigates, after investigating current writing, distinguished critical partners, counting but not limited to government and its parastatals, NGOs, benefactors, the private segment, media, the scholarly world, territorial collaboration, community / citizen and the prompt environment. Based on the concept of partners, the acceptance that much might be fulfilled within the locale of calamity administration in case all partners are completely recognized, well-coordinated and regarded. In conclusion, this inquires about offers supportive information on the part of partners in relieving the rate of catastrophes to ensure productive administration of fiascos.
\end{abstract}

Keywords: Disaster, Prevalence, Role, Stakeholder.

\section{INTRODUCTION}

Catastrophes are of diverse sorts and this clarifies the reality that there will diverse ways of overseeing. The chance is ordinarily characterized as a 'possibility of harm.' Be that as it may, inside the setting of fiascos, the hazard is the likelihood of noteworthy hurts being reeled out from the perilous occasions, such as passing, financial misfortunes, wounds, environmental weakening, and devastation of food. Thereupon, the term calamity hazard is, to say the slightest, exceptionally multidisciplinary and may as well be utilized in an assortment of settings (UNDP, 1992; Mal et al., 2018). It is of the see that a few callings too characterize chance in different measurements, which the definitions that are given to hazard depending on the setting of the proficient calling (Kelman, 2003; Paton and Johnston, 2017). Firstly, with regard to the angle of the fiasco, risk mitigations have specific contemplations. Concurring to UNDP (1992), sees chance as that which generally related to a person's failure to bargain with a certain condition. Along the same vein, the chance is being seen as that which grasps associates to dangers, adversarial or undesirable forecasts, and the conditions that contribute to peril (Hewitt, 1997; Krüger et al., 2015). It is assist being broadly perceived that in arrange for catastrophe chance moderation to be solid, it ought to be down to earth at the neighbourhood or community level.

Catastrophe administration is a coordinates handle of arranging, sorting out, planning and executing measures to viably bargain with their effect on individuals (Deshmukh et al., 2008). The fundamental stages of catastrophe administration are characterized as long-term relief, readiness, help, and reproduction. Relief or chance 
diminishment exercises incorporate auxiliary and non-structural measures to diminish the unfavourable impacts of common risks (Atmanand, 2003; Bosher et al., 2009; Moe et al., 2007). Readiness bargains with exercises and measures taken in progress to ensure agent response to the impact of dangers, counting the issuance of opportune and compelling early notices and brief clearing of individuals and property from undermined areas (Atmanand, 2003; Moe et al., 2007). Arrangement of help or association all through or after a calamity to light the life security and fundamental living needs of those influenced are given amid the alleviation stage. Redesign signifies the remaking of the overstated existing circumstances of the overstated civilization with the point of long-term supportability (Moe et al., 2007).

As a matter of reality, when considering the different aspects of fiasco administration the part of the different partners included within the whole prepare cannot be belittled (Khan et al, 2008). This incorporates the government segment, parastatals, and indeed the parliament. A compelling collaboration among the partners has been portrayed as a powerful driver for viable catastrophe administration and moderation (Moe et al., 2007; Mojtahedi, 2014). Diverse analysts have categorized disaster administration partners in numerous ways (Mojtahedi, 2014; Fontainha et al., 2017). It is deliberate of this thing about to blend these different categories as mined from the past think about. This, in any case, appears to be the most commitment of information ponder.

Resulting to the over, this think about is set out to efficiently reel out from past ponders the key partners as well as their parts in catastrophe administration and moderation. In arrange to achieve this assignment, the complete article is separated into 4 parts to be specific: an introduction which gives common see to the catchphrases within the point; components of fiasco controlling which incorporate mindfulness, reaction, and recuperation; taken after by a discourse on the substance and significance of stakeholders' hypothesis. Another area contains the classification of catastrophe administration partners as well as their parts whereas the final portion of the paper centers on the conclusion. This ponder is put input to include its see to the existing writing on the requirement for compelling coordination of the different partners with a see to improving fiasco event as well as guaranteeing successful administration.

\section{RESEARCH METHODOLOGY}

\subsection{Disaster management and mitigation}

Calamity administration and moderation are for the most part made up of 3 components specifically; status, response, and recovery. Status works out incorporate making emergency frameworks and accomplice regulation capacity ahead of time so as to progress a defensive response to the negative effect of calamities. Works out join making cautioning systems, recognizing clearing courses and secure houses, keeping up emergency supplies and correspondence systems, and coordinating calamity exercises to taught and get ready staff, organize pioneers and locals (Ainuddin et al., 2012). A thankful level in a proactive way to bargain with calamities makes a difference to decrease passing's, wounds, property hurt and misfortune of cash. Preparation recognizes the nearness of remaining, unmitigated hazards, and tries to assist society in wiping out certain troublesome impacts that can be experienced once a physical event happens (Look, 2002; Twigg, 2015).

Response implies works out taken expeditiously in the midst of and taking after adversity. The elemental objective of a capable response to a catastrophe is to save the arrangement and decrease hurt. Response works out allow help in the midst of or expeditiously after a catastrophe to meet the existing preservation and basic subsistence needs of those people impacted (Moe, 2006). Essentially, response works out join starting the emergency assignment plan and centre, purging and protecting casualties, looking for, defending and giving remedial care (Look, 2002). Haddow (2017), appeared that activating emergency centres fittingly, purging undermined populaces and vehicles, working havens, evaluating financial hurt, executing effective coordination's organization and actualizing compelling planning and apportioning of resources are basic in the midst of response works out. The fruitful joint exertion between catastrophe response accomplices, counting the neighborhood masses, adjacent chambers, and charitable affiliations could be a crucial piece of response works out (Martel, 2016).

Recovery works out recognize with reclamation in here and presently and diversion in long-haul tries which went for re-establishing essential sincerely strong systems and returning life to conventional. These work out cover changing private and non-private structures, lanes, expansions, and establishment, and arranging authoritative works out (Mileski et al., 2018). Accomplices frequently take the responsive framework to supervise fiascos (Šakić et al., 
2018). The examination furthermore focused that post-fiasco recovery gives a chance of reducing the threat of calamities and for progressing flexible restraint. Post-debacle incline diversion as shown by Mileski et al. (2018) takes out squander, upgrades the nature of the manufactured condition, smoothens the work handle and progresses the execution of post-fiasco changing in misfortune organization. Wieringa et al. (2016), found that creating passing workplaces, actualizing an execution expect post-debacle redoing, and documenting works out learned are the works out most sharpened by accomplices within the recovery organize after calamities. In conclusion, calamity administration and moderation prepare include a wide extend of exercises that unquestionably will include a great number of partners.

\subsection{Stakeholder definition and its relevance to effective disaster management}

The significant meaning of a partner is "any gathering or individual who can impact or is impacted by the achievement of the association's objectives" (Bostick et al., 2018). The common thought of the partner thought could be a redefinition of the affiliation. Fundamentally, the idea is almost what the association got to be and how it got to be conceptualized. The partner thought has picked up a wide reputation among scholastics, media, and chief within the zone of the successful satisfaction of errands because it is acclaimed of prepared for changing the organization sharpen (Ha et al., 2016). Besides, the affiliation itself got to be to bargain with their advantage, needs, and points of view.

Stoney \& Winstanley (2001) characterized partners as those get-togethers with tall satisfactory impacts in an affiliation that would make that affiliation halt to exist without the partner's offer assistance. Bostick et al. (2018) portrayed a partner in affiliation as "any gathering or individual who can impact or is influenced by the achievement of the association's objectives". Hazarika et al. (2018) communicated that "a partner is a person, gathering, or affiliation who may impact, be influenced by, or comprehend itself to be affected by a choice, activity or the result of an undertaking. The Venture Administration Body of Information taken notes that an errand has various accomplices whose interface can be associated, or within the battle. The conspicuous confirmation and organization of such accomplices, in this way, turn into a liberal capacity for any affiliation in a crisis.

\subsection{Stakeholder Theory and Disaster Management}

A broad writing audit and cautious reflection uncovered two measurements for surrounding and naming categories of fiasco organization a concern for handle and concern for instruments. The categorization of hypothesis in catastrophe inquire about in this content is assembled along with these two measurements, in four categories. The primary category is the writing on choice making and decision hypothesis, which is additionally the biggest of the categories. The moment category centres on administration and administration and is named regulatory speculations. The third category includes social speculations; counting composing that laments the state of the writing as an entirety and calls for more/better science, more/better estimating, and more/better advancement of speculations and hones to address social angles of fiasco and emergency. The fourth category of hypothesis in catastrophe investigate, named financial speculations, may freely be portrayed as a cluster of asset financial matters hypotheses and is additionally the littlest of the bunches.

Choice speculations, as portrayed in this investigate, allude to approaches to catastrophe and emergency that most frequently depend on an arrangement of stages, steps, heuristics, or strategies to get it, depict, or adapt to the emergency or fiasco. This quadrant contains a number of data-driven, outcome-based approaches counting choice-making, fulfilling, and other information seriously approaches. Authoritative hypotheses, in differentiate, tend moreover to stress forms as well as apparatuses, instead of centering on certain utilitarian results only. Financial speculations in this setting speak to curiously reflections, thought tests, and other approaches to fiasco and emergency that frequently need the utilitarian results of choice speculations, making them useful fundamentally as a mode of portrayal instead of a mode of activity. At last, social speculations tend to be nearly completely prepare situated, centering on strategies of activity instead of classical results (moderation, repair, alleviation). These social speculations tend to be most valuable for reflection and talk. In substance, the choice and authoritative speculations are caught on as having basically a strategic centre; the financial and social hypotheses underline a key or unique centre. All these hypotheses as they relate to the course of the study are assist examined within the ensuing sections.

\subsubsection{Decision theory}

One of the most common modes of study for theorizing about crisis and disaster involves choice hypotheses. They are significant as devices to arrive at certain normally comprehended utilitarian objectives, yet regularly have 
little worry for the procedures used to contact them. These hypotheses rise up out of the standard basic leadership writing, for example, the great research by Simon (1976), Allison (1971), Cohen et al. (1972), and numerous others. Research around there will in general casing and reframe calamity and emergency hypotheses from the settings of recognition (Barnett et al., 2005), data get to (Anand and Forshner, 1995), just as issues of information quality and the contemporary condition of research (Smith, 2006). One rapidly finds that the settings are changed. It incorporates talks of mad cow illness (Anand and Forshner, 1995), general wellbeing (Barnett et al., 2005), and the requirement for better devices, for example, GIS (geographic data frameworks) and remote detecting innovation, the advantages of utilizing re-enactments (Smith, 2004),adaptation and the use of frameworks hypothesis (Petak, 1985).

In any case, notwithstanding this assortment, a large portion of these settings speak to minimal more than direct utilization of ideas, for example, fulfilling, basic leadership under vulnerability (Anand and Forshner, 1995), and chance observation and nervousness (Barnett et al., 2005) that have changed next to no from when they were first created by Bernoulli (1954), and Simon (1976). Thusly, we find that the choice 'hypotheses' of emergency and calamity experience the ill effects of most, if not all, of the issues tormenting the arrangement writing: a dependence on top-down approaches, creation line models, and other hyper-level headed structures (Miller, 2002), and an overall disregard of procedure based concerns. These arranged objective models, or all the more properly heuristics or instruments, by and by neglect to include anything besides the nuts and bolts of the issues, setting, and substance encompassing emergencies and debacles.

In the meantime, the choice hypothesis order of the fiasco and emergency writing is very cognizant. It reliably mirrors the objectives and aim of the prior grant. In any case, it offers valuable little from the viewpoint of hypothesis advancement, speculating, or investigate. Rather it will in general support application, assessment and utilization predictable with the majority of the top-down, information-driven, or generally observational ways to deal with basic leadership that has educated writing in the sociologies for a considerable length of time. A striking special case to this is crafted by Paraskevas (2006), who presents some dialog of intricacy hypothesis to the writing. This exemption, obviously, offers some proof for why there is such a dependence on old-style and neoclassical ways to deal with hypotheses of emergency and catastrophe. One may contend that as a field of study, emergency and debacle the board is still in its early stages and advancement. Proceeding with the improvement of a scientific classification (Huffman, 1989) would give a genuinely necessary premise to its advancement as an interdisciplinary field of study.

\subsubsection{Administrative theory}

Another common area of research in crisis and disaster falls under the heading of administrative speculations, which incorporate administration hypotheses, authority speculations, and morals. This incorporates researchers who articulate the requirement for authority, for change, and for long haul change just as the individuals who commotion for the advancement of emergency administration capabilities (James and Wooten, 2005). This class has the disastrous issue of being connected with one of the most vigorously inspected at this point inadequately comprehended regions of authoritative writing, making it risky as a field of inquiry given the present condition of the administration writing when all is said in done. For instance, on the off chance that one starts with a large number of approaches to characterize authority (Rost, 1991) and afterward considers the standard discussion in regards to the idea of administration and whether it tends to be educated, one rapidly finds that, at its centre, utilizing initiative as a reason for guessing about emergency and calamity is much the same as building a house on sand.

Thus, the shortcomings in the initiative writing are comprehended and are being examined (Fairholm, 2004; Van Wart, 2003), offering some desire for later use in a debacle organization. Maybe, on the off chance that one rather considers writing on administration simultaneously with the improvement of writing on emergency or debacle the board, they could frame an advantageous relationship. On the off chance that initiative is, indeed, adapting to change (Milner and Joyce, 2005), and catastrophe and its originations have experienced intense changes as verbalized by Quarantelli and Dynes (1977), at that point, there could be some help for building up the two collections of writing a couple. As opposed to accepting that authority studies ought to consequently advise fiasco and emergency hypothesis, we may rather utilize the open doors that such occasions manage the cost of us to all the more likely comprehend the two marvels in a synergistic or corresponding manner instead of from an exacting straight approach.

Also, it could be advantageous to start investigating how to consolidate administration and different collections of writing to help advise the more extensive comprehension regarding emergency and fiasco. One such model originates from crafted by Smits and Ezzat-Ally (2003) who joined exchanges of job hypothesis, learning hypothesis, and components of choice speculations with an authority concentrate to show what they call 'status.' 
Readiness is an element of job information, preparing, a mix of jobs and obligations that prompts practiced, reasonable, and steady practices facilitated at all levels of the association. Research, for example, offers a few advances for the improvement of down to earth hypothesis, if not high hypothesis (managing exceptionally conceptual wide ideas), accordingly expanding the possibility to push emergency and catastrophe hypothesis toward a progressively full-grown comprehension. A lot of the writing on emergency and calamity hypothesis will in general centre on explicit administrative challenges. The most essential test, obviously, encompasses the need to modify and react in a convenient manner (Moore and Lakha, 2006). All the more as of late, Drabek (1985) recognized issues of coordination among the existing workforce, structures and crisis responders with regards to groups and research on decentralization.

Besides, Voogd (2004) expands on this, featuring the restrictions of direction and control based catastrophe counteractive action frameworks, while featuring how decentralization can be an indispensable piece of the procedure. Moreover, Smith (2004) coordinated discourses of supervisory crews into reproduction forms as a system to give down to earth bits of knowledge that help catastrophe hypothesis. Past this standard, the executive's issues, there as of late has been some enthusiasm for creating, clarifying and understanding the moral gives that encompass calamities and emergencies. Kysar and McGarity (2006), for instance, talk about the ramifications of lawful activity, basic leadership and managerial duty considering the Katrina fiasco. Also, their work brings up issues about whether climatic fiascos, for example, storms can be reliably anticipated and assessed utilizing logical strategies, opening the likelihood for elective methods of inquiry. On the off chance that one next spotlight all the more intently on the general rubric/talks of the New Public Management (NPM), we find that it also rises as a subset of the administrative classification. Review that the fundamental teaching of NPM incorporates some positive requirement for entrepreneurialism, execution measures, deregulation and decentralization, solid yield controls, and stringent powers over assets (Milner and Joyce, 2005).

Notwithstanding, in specific conditions, these thoughts of proficiency and streamlined activities have a specific implied claim, especially when recuperation endeavors become buried in administrative snags, amazing negative symbolism, and social distress. Smith (2006) wails over the ebb and flow condition of the debacle the board 'science' (not the board science comprehended similar to a piece of activities inquire about), pushing the utilization of execution planning as a way to improve things, reliable with standard NPM beliefs. Fundamentally, Smith offers us a reasonable connection from the calamity writing to the standard open organization writing through the language and practices of NPM and its scholarly progenitors, along these lines further fortifying the apparent estimation of the administrative hypotheses in the authoritative classification.

\subsubsection{Theory of natural disaster}

The monetary hypothesis of the catastrophic event focuses on the manners by which nations are influenced by cataclysmic events, contingent upon their financial attributes, their degree of advancement, and their intrinsic degrees of catastrophic event chance (Kellenberg, and Mobarak, 2011). The hypothesis additionally investigates different parts of ex bet catastrophe alleviation, for example, enhancements in cataclysmic event hazard data and cataclysmic event protection markets, just as ex present reactions on the cataclysmic event as post debacle help and since a long time ago run development possibilities. As indicated by Anbarci et al. (2005), since 1970 there have been in excess of 9,800 catastrophic events around the world, murdering more than 3.7 million individuals, influencing more than 5.8 billion individuals, and causing more than $\$ 1.7$ trillion in assessed harms, and the numbers are relentlessly expanding.

The hypothesis endeavours to investigate the effect of catastrophic events on a nation. As needs are, there are a few manners by which a nation is affected by a cataclysmic event; examine is separated on whether a catastrophic event is valuable for a nation all in all. In the short run, as per Raddatz (2007), certain fiasco stuns, including climatic debacles, for example, dry seasons, outrageous temperature occasions, windstorms, and floods, can significantly affect per-capita GDP. Such climatic debacles bring about a normal genuine per-capita salary loss of $2 \%$, though philanthropic fiascos, for example, starvations or scourges bring about a normal genuine per-capita pay loss of $4 \%$ in the short run. Skidmore and Toya (2002), conversely, contend that GDP doesn't represent harm to capital and solid merchandise in the short run; for sure, the expansion of new capital in the quick-term may build GDP. Skidmore and Toya (2002) likewise locate a positive relationship between catastrophic events and development over the long haul. Utilizing a board informational index on 89 nations, they first take a gander at the impacts of fiasco occasions on GDP/per-capita development rates and locate that climatic catastrophes have a positive and noteworthy impact on development rates. 
Since quite a while ago run development rates might be influenced as more up to date and progressively gainful advancements supplant obsolete ones. In spite of the obliteration of capital, catastrophes increment the arrival to human capital comparative with speculation capital and increment all out factor efficiency through the selection of fresher and progressively beneficial innovations (Skidmore and Toya, 2002). The exploration discoveries subsequently feature significant macroeconomic channels through which nations may develop following disastrous catastrophic events. Hallegatte and Dumas (2009) contend that this propensity leaves since a long time ago run profitability unaltered contrasted and pre-calamity levels. This pattern shows how low-salary nations that experience the ill effects of regular fiascos are in danger of getting stuck in a neediness trap. They ceaselessly supplant harmed capital with capital like what existed before the fiasco so as to continue earlier degrees of profitability as fast as could be allowed. This, be that as it may, limits the probability of future increments inefficiency.

Cataclysmic events additionally influence work markets. Utilizing a board informational collection on floods over the United States, Sarmiento (2007) shows that overall, total nearby business falls by $3.4 \%$ after a flood occasion as labourers escape the region. Salary levels, in any case, increment following a calamity, as indicated by Belasen and Polachek (2009). There is additionally writing on the mental effects of cataclysmic events. Luechinger and Raschky (2009) use information from an actual existence fulfilment overview to esteem flood calamities. In particular, they utilize the way to deal with adapt utility loses for 16 European nations somewhere in the range of 1973 and 1998 and contrast the outcomes and information on floods in the United States. As anyone might expect, the creators find that flood fiascos have a measurably noteworthy negative impact on life fulfilment, in spite of the fact that this impact reduces as salary increments. They find that the normal readiness to pay to anticipate one calamity occasion in the locale of habitation is $\$ 6,505$, the likeness $23.7 \%$ of normal salary.

Carroll et al. (2009) additionally use life fulfilment review information to measure the financial misfortunes related to catastrophes. In particular, they take a gander at the impacts of dry spells on life fulfilment in Australia somewhere in the range of 2001 and 2004. They find that in rustic zones if a dry season happens in the springtime (rather than some other time in the year), it has a negative and measurably huge impact on life fulfilment-proportionate to losing $\$ 14,500$ of salary for provincial family units. They utilize this gauge to anticipate that the normal multiplying of dry springs after 2020 will prompt a 1\% drop in Australia's GDP. The financial hypothesis of debacle likewise recognizes territory of future research (hole) to remember to investigate for the money-saving advantage examination of arrangements on fiasco the board, part of neediness and debasement in calamity decrease just as refinement in the protection markets (Kellenberg and Mobarak, 2011).

\subsubsection{Stakeholder theory}

The key meaning of a partner is "any gathering or person who can influence or is influenced by the accomplishment of the association's goals" (Freeman, 1984). The general thought of the partner idea is a redefinition of the association. Basically, the idea is about what the association ought to be and how it ought to be conceptualized. The partner idea has increased broad notoriety among scholastics, media and administrators in the territory of effective finishing of activities as it is acclaimed of fit for changing administration practice (Friedman and Miles, 2006). Friedman and Miles (2006) expressed that the association itself ought to be to deal with their advantage, needs, and perspectives. Partner the executives are believed to be satisfied by the administrator of a firm. The administrator ought to deal with the company on one hand for the enthusiasm of its partners so as to verify their privileges and the help in basic leadership and furthermore, the power must go about as the investor's operator to guarantee the endurance of the firm to ensure the long haul of each gathering.

The idea of a partner in the previous scarcely any years has blasted a great deal and scholastics had composed broadly on the idea. Likewise, Non-Governmental organizations (NGOs), controllers, media, businesses, and policymakers discover the idea vital. In crafted by Friedman and Miles (2006), it was presented that a typical method for separating the various types of partners is to consider gatherings of individuals who have a classifiable association with the association or task. They went further by drawing a reasonable connection between meanings of what partners and distinguishing proof of who are the partners which incorporate customer, representatives, contractual worker, providers and temporary workers/advisor and different investors in understanding to the association or undertaking. It very well may be reasoned that investors are those required in an association or venture to fill in as a group to guarantee effective fulfilment inside the set space of time. The thought of partner hypothesis was at first created from a scholastic research stream being attempted in the US during the 1960s that characterized partners as those gatherings with high adequate impacts in an association that would make that association stop to exist without their (the partners) support (Li et al., 1994; Stoney and Winstanley, 2001). Afterward, Freeman (1984) expanded this definition and 
portrayed a partner in an association as "any gathering or person who can influence or is impacted by the accomplishment of the association's destinations". The Project Management Institute (PMI) embraced this definition and expressed that "a partner is an individual, gathering, or association who may influence, be impacted by, or comprehend itself to be affected by a choice, movement, or result of a venture" (Hwang and Ng 2013). The Project Management Body of Knowledge (PMBOK) noticed that an undertaking has numerous partners whose interests might be connected, or in struggle (PMI, 2013).

The recognizable proof and the executives of such partners, in this manner, become a generous capacity for any association in an emergency. It is likewise contended that an association's preferences are basically respondents on its capacity to sufficiently oversee partners (Verbeke and Tung, 2013). This investigation accepts that the hypothesis can be of help where the standards are strictly followed in accomplishing compelling graveyard the board. The outline of the hypothesis appears in Table 1.

Table 1: Summary of the underpinning theory

\begin{tabular}{cl}
\hline \hline Name & \multicolumn{2}{l}{ Stakeholder Theory } \\
\hline Year & 1983 \\
\hline Authors & Freeman, 1984; Donaldson and Preston, 1995; Freeman et al. (2010) \\
\hline $\begin{array}{c}\text { The thrust of } \\
\text { the theory }\end{array}$ & $\begin{array}{l}\text { The standard of who or what truly means the development of a business concern } \\
\text { or non-benefit making association doesn't just lay on the proprietors or investors } \\
\text { yet different gatherings also like representatives, clients, providers, lenders, } \\
\text { networks, legislative bodies, political gatherings, exchange affiliations, worker's } \\
\text { organization, and even contenders. } \\
\text { Their status is gotten from their ability to influence the firm/association and its } \\
\text { partners. }\end{array}$ \\
\hline
\end{tabular}

Application of the theory

- Stakeholder hypothesis prevails with regards to turning out to be celebrated in the business morals fields, yet it is additionally utilized as one of the structures incorporate social duty strategies.

- In the field, for example, law, the board, human asset, partner hypothesis prevailing with regards to testing the standard investigation structures by recommending to put partners' needs toward the start of any activity.

- In the field of business morals, Weiss (2014) shows how partner investigation can be supplemented with issues identifying with the board ways to deal with look at cultural, authoritative, and singular situations.

- Stakeholder hypothesis has additionally observed developing upkeep in higher instruction in the late twentieth and mid- $21^{\text {st }}$ hundreds of years.

- From the previous, the importance of partner hypothesis in the fiasco the board and relief is viewed as gigantic. Collaboration among those that issue in the process will be of incredible favourable position.

Criticism/

Limitation
- Charles Blattberg (as referred to in Friedman and Miles (2002) scrutinized partner hypothesis for accepting that the enthusiasm of the different partners can be, best-case scenario, traded off or adjusted against one another as he discovered it as a result of its accentuation on arrangement as the main method of exchange for managing clashes between partner intrigue.

- Mansell (2013) brought up that by applying the political idea of an "implicit agreement" to the company, the partner hypothesis undermines the standards on which a market economy is based. 


\subsubsection{Stakeholder in disaster management and mitigation}

With the end goal of this examination, the audit of the writing has called attention to the way that different classifications of partners exist in a fiasco the board. Subsequently, the partners' hypothesis is received as the supporting hypothesis to commute home the requirement for the solidarity or potentially collaboration that is relied upon to exist among the recognized partners. Every one of the partners ought to be viewed as having a similar right to data and basic leadership in issues identifying with calamity the board. With the hypothesis been effectively received and applied in numerous orders as exhibited in Table 1, the situation of this investigation is that if the principles of the hypothesis are strictly pursued, it is fit for aiding fiasco the executives and alleviation. Government and its authorities are relied upon to convey different partners along particularly the individuals/networks who are as a rule at the less than desirable end. The job of the private segment additionally should not be undermined. The legislature must respect their expert guidance to improve the business as usual.

\section{METHODOLOGY}

The procedure embraced for this investigation was by utilizing a survey of the existent writing, this work examines calamity hypotheses and their applications in the fabricated condition to give valuable data identified with the job of partners in alleviating catastrophe commonness to guarantee successful fiasco the executives for seeing partners' proactive as well as receptive methodologies in a debacle hazard decrease.

\section{RESULTS AND DISCUSSION}

\subsection{Stakeholders in Disaster Management and Mitigation}

With the end goal of this examination, the audit of the writing has brought up the way that different classes of partners exist in a debacle the executives. Government and its authorities are relied upon to convey different partners along particularly the individuals/networks who are as a rule at the less than desirable end. The job of the private division likewise should not be undermined. The administration must respect their expert guidance to improve the business as usual. Figure 1 is displayed to outline various ways by which various creators classify partners in misfortune the executives with the end goal of mining the by and large referenced ones to fill in as a structure for this examination. Looking into the literation, this investigation found that the classification of partners associated with fiasco the executives varies in introduction from one specialist to the next.

\subsection{Investigation of the Role of Stakeholders in Mitigating Disaster Prevalence}

According to Mojtahedi et al. (2017), a partner is said to join any component without the assistance of which an affiliation would not endure. Stakeholders opined that accomplices have an eagerness for the exercises of an establishment and that they can affect or be impacted by the achievement of the affiliation's destinations (Al-Fadhali et al., 2017; Najib et al., 2018; Al-Fadhali et al., 2019). Harrison et al. (2015) detailed the significance of an accomplice from another edge by depicting him as a man or a component who gives a commitment to the essential authority and furthermore who benefits by the eventual outcomes of decision makings. From the earlier, thusly, relating the possibility of partners to disaster organization, it suggests individuals, get-togethers or affiliations who may impact, be affected by or see themselves to be affected by the impacts of disasters. By enlargement, any kind of substance that is viably connected with regulating cataclysm beforehand, in the midst of and after events or whose interests may be unfavourably impacted in the consequence of a calamity can be an accomplice in a disaster chance organization (Reyers et al., 2015). Thusly, close by people, get-togethers, affiliations, foundations, social requests, and even the standard environment are all around thought to qualify as authentic or potential partners (Mojtahedi et al., 2017).

\subsection{The Role of Stakeholders in Mitigating Disaster Prevalence}

Fiasco hazard the board has been sorted in various ways by various specialists. For example, (Mojtahedi et al., 2017) exhibit how these seven accomplice packs possibly are mapped or agreed with other partner orders (for example private/open part, strategy/professional, casual/formal, local gatherings/people). Nonetheless, from the accessible writing looked into, the accompanying outline can be made in regards to the rundown of partners in 
relieving calamity predominance just as their essential jobs.

\subsubsection{Government at Different Levels}

Basically, thinking about the key partners in misfortune the executives and alleviation, various levels of government frames the bleeding edge. This cuts transversely over Federal, State, and Local specialists. Basically, the activities and focuses of the administration, state, and close by emergency organization associations rely upon an intensive emergency organization appear. The model segments the emergency organization's work into four phases (Shaw, 2012).

- Mitigation - assessing the peril posed by threat or potential disaster and trying to diminish the risk;

- Preparedness- - developing a response configuration in perspective on the peril examination, planning response staff, engineering major resources, making strategies with various districts for sharing of advantages, explaining jurisdictional commitments, and so on;

- $\quad$ Response - executing the plans, lessening the potential for helper damage, and making arrangements for the recovery organize; and

- Recovery - re-establishing life genuinely strong systems, for instance, fixing electrical power composes and giving the ephemeral hotel, sustenance, and articles of clothing. Recovery is acknowledged to keep down before changing.

Because of the relentless event of normal and man-made catastrophes or the way that no nation is said not to be safe to either characteristic or man-made debacle or both, nations around the globe have concocted a system of setting out Disaster Management units under various name with point of giving quick reaction and however much as could be expected support preventive measures (Islam and Walkerden, 2015). Subsequently, the administration has it as a culture to a yearly premise, the spending limit impressive sum with the end goal of catastrophe the board. The national parliament is additionally engaged with this classification. National parliament ought to be utilitarian, with the full venture of both position and obstruction people. Disaster organization is a level-headed explanation and there must be bi-partitioned accord over the basic issues. The parliamentary board must have its controlling and supervisory impact. In this particular situation, the regular society, the academic world, and the NGOs need to put strong weight, with the objective that the parliament and its blocks of trustees wind utilizing.

\subsubsection{Role of Non-Governmental Organizations (NGOs)}

The Disaster Management unit under some random nation is commonly doled out the piece of sorting out the NGO works out. NGOs make up an enthusiastic part in any economy, especially making nations, which has been acclaimed by and large (Renaud et al., 2013). NGOs are successfully required, among others, in a failure organization, little scale credits, family orchestrating, human rights, etc. In fact, the methodology of NGO practices in any country of the world can't be put down. Thus, their dedication, particularly to the social organization division and arrangement of needy individuals, is entirely perceptible, and this has been acclaimed by the worldwide system. NGOs Disaster Forum is particularly connected with various activities in pre-, in the midst of, and post-disaster works out (Athukorala, 2012). Various parts of NGOs consolidate support, state-financed guidance campaigns, and planning programs for the workforce drew in with disaster organizations beginning from the national to the affiliation or system level. NGOs are furthermore powerful in emergency flight and ensuring of the setbacks. The post-fiasco practices fuse offering new scaled downscale credits or rescheduling their portion programs for recuperation.

\subsubsection{Job of Donors in Disaster Management}

Suppliers are a basic accomplice being created organization in the making economy, particularly in the fiasco organization portion, both at the national and the local levels (Alexander, 2014). Worldwide help is given to impact countries following every genuine disaster in view of the Government's sales for easing, recuperation, and propagation. Such help has been given by the UN workplaces, among administrative and corresponding headway assistants. Starting late, there is a Disaster Response Group, made out of provider designates and headed by the UNDP Resident Representative in different parts of the world (Athukorala, 2012). The improvement associates offered assistance to the various pieces of fiasco both for alleviation and revolution, which went for reducing the peril of genuine normal and man-made. Help from the International Federation of Red Cross/Crescent Societies has bolstered disaster in different countries. Throughout the years, the job of worldwide and nearby givers has assumed a colossal job in a debacle aversion just as a relief which comes for the most part from UNDP, UNESCO and World Bank among others. 


\subsubsection{Media}

The media is another significant partner, distinguished in the writing, in a fiasco the executives from one nation to the next (Alexander, 2014). Media support has been dynamic in circulating news, particularly on postdisaster impact. There has been somewhat advancing in granting messages by the media on disaster hard diminishment. Mojtahedi et al. (2017) Prescribe for the media to "include a basic course in the media for people to take after". In such a way, media delegates need to hone themselves, first through getting ready projects on ways and techniques for cataclysm risk diminishment. At precisely that point they would have the ability to finish reasonable correspondence with individuals when all is said in done and notwithstanding the council (O'Leary, 2004).

\subsubsection{The scholarly world}

The collaboration of the insightful world which has been perceived to be so far obliged has been accepted to be incredibly huge in disaster organization (Mojtahedi et al., 2014). The association between the material educational and inquire about the system with national or neighbourhood foundations overseeing fiasco reducing is vehemently significant. Some academic and research organizations in different countries are creating such associations (Coppola, 2006). The insightful world, with formally some institutional assistance at both open and private school levels, has the best potential to add to risk showing, danger assessment, calamity recovery parts and furthermore to making planning modules for different levels of the breaking point building. Each and every other accomplice, for instance, the Government Organizations (GO), NGO, the private division, media, and suppliers will benefit by a relationship with the insightful world (Haworth and Bruce, 2015).

\subsubsection{The private sector}

The private division as indicated by Mojtahedi et al. (2017) is ordered as lethargic partners as they are portrayed to have by zero correspondence with an affiliation; they can drive their will on affiliation and their ability remains unused (Busch et al., 2013). The private territories fuse various specialists in altering, financing, and promoting. Private part administrators the makers, agents, structure engineers, insurance masters, agriculturists, and voyager office owners must be procured the essential initiative and execution endeavours through consistent affiliations constantly.

In a given masterminded adventure on Sustainable Development and Disaster Risk Reduction for the most unfortunate, the organization means to progress budgetary and fiscal instruments remembering the private part for cataclysm organization. Insurance is seen as a dug-in an instrument for chance trade, yet access to the proper assurance grandstand by the poor isn't generally a reality. This nonappearance of insurance scope and the weak social prosperity nets in the country induce an unusual condition of weakness, which is simply exacerbated by risks of disastrous occasions. 


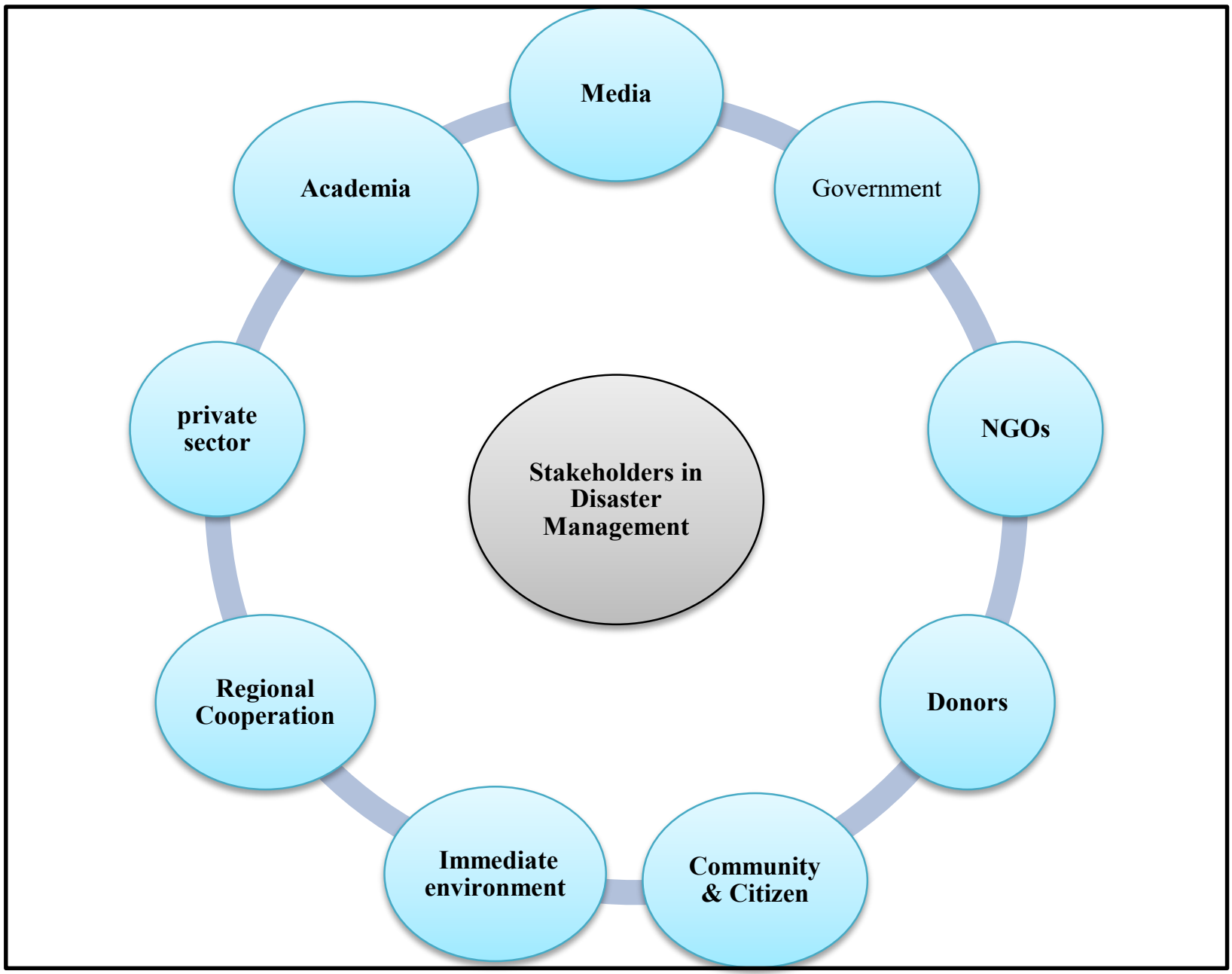

Figure 1: Stakeholders in Disaster Management

\section{CONCLUSION}

This examination was set to propose one of the significant methods for overseeing and moderating both common and man-made calamity which is through viable coordination among the partners associated with fiasco the executives. This examination had the option to evaluate past investigations on this topic and found that the key partners in calamity the board to include: government and its parastatal, NGOs, givers, the private area, media, the scholarly world, provincial participation, network/resident and the prompt condition. The fundamental of partners' hypothesis was received to uncover the advantages of inalienable in well-organized partners. This examination has faith in the supposition that debacle related to nature could be definitely decreased if not destroyed where the privilege of every partner is very much regarded and its job is enough characterized. This examination can be helpful to the administration in making pertinent arrangements identifying with catastrophe the executives by including every one of the partners to guarantee appropriate execution. With the end goal of future research, an experimental examination is prescribed to decide how pertinent every partner is in a fiasco to the executives. In future work, the creators expect to make more examination the job of partners with respect to catastrophe the executives decrease by directing the quantitative investigation.

\section{REFERENCES}

Ainuddin, S., \& Routray, J. K. (2012). Institutional framework, key stakeholders and community preparedness for 
earthquake-induced disaster management in Balochistan. Disaster Prevention and Management: An International Journal, 21(1), 22-36.

Alexander, D. E. (2014). Social media in disaster risk reduction and crisis management. Science and engineering ethics, 20(3), 717-733.

Al-Fadhali, N., Mansir, D., \& Zainal, R. (2019). Validation of an integrated influential factors (IIFs) model as a panacea to curb projects completion delay in Yemen. Journal of Science and Technology Policy Management.

Al-Fadhali, N., Zainal, R., Kasim, N., Dodo, M., Kim Soon, N., \& Hasaballah, A. H. A. (2019). The desirability of Integrated Influential Factors (IIFs) Model of internal stakeholder as a panacea to project completion delay in Yemen. International Journal of Construction Management, 19(2), 128-136.

Andrew, S. A., \& Hawkins, C. V. (2013). Regional cooperation and multilateral agreements in the provision of public safety. The American Review of Public Administration, 43(4), 460-475

Athukorala, P. C. (2012). Indian Ocean tsunami: Disaster, generosity, and recovery. Asian Economic Journal, 26(3), 211-231.

Atmanand (2003) Insurance and Disaster Management: The Indian Context. Disaster Prevention and Management, $12(4), 286-304$.

Bosher, L., Dainty, A., Carrillo, P. \& Glass, J. (2007) Built-in Resilience to Disasters: A PreEmptive Approach. Engineering, Construction and Architectural Management, 14 (5), 434- 446.

Bosher, L., Dainty, A., Carrillo, P., Glass, J. \& Price, A. (2009). Attaining improved resilience to floods: a proactive multi-stakeholder approach, Disaster Prevention Management. 18: 9-22.

Bostick, T. P., Holzer, T. H., \& Sarkani, S. (2017). Enabling stakeholder involvement in coastal disaster resilience planning. Risk analysis, 37(6), 1181-1200.

Busch, N. E., \& Givens, A. D. (2013). Achieving resilience in disaster management: the role of public-private partnerships. Journal of Strategic Security, 6(2), 1.

Coppola, D. P. (2006). Introduction to international disaster management. Elsevier

Cutter, S. L. (2012). Hazards vulnerability and environmental justice. Routledge.

Deshmukh, R., Rodrigues, L. L. R. \& Krishnamurthy, G. R. (2008) Earthquake Risk, and Knowledge Management. Journal of Knowledge Management Practice, 9 (3).

Donaldson, T., \& Preston, L. E. (1995). The stakeholder theory of the corporation: Concepts, evidence, and implications. Academy of Management Review, 20(1), 65-91.

Fontainha, T. C., Leiras, A., de Mello Bandeira, R. A., \& Scavarda, L. F. (2017). Public-private-people relationship stakeholder model for disaster and humanitarian operations. International Journal of Disaster Risk Reduction, 22, 371-386. 
Freeman, R. E., Harrison, J. S., Wicks, A. C., Parmar, B. L., \& De Colle, S. (2010). Stakeholder theory: The state of the art. Cambridge University Press.

Freeman, R.E. (1984), Strategic Management: A Stakeholder Approach, Pitman Publishing Company, MA

Friedman, A. L., \& Miles, S. (2002) “Developing stakeholder Theory. Journal of Management Studies, 39(1):1-21

Friedman, A. L., \& Miles, S. (2006). Stakeholders: Theory and practice. Oxford University Press on Demand.

Ha, K. M. (2016). Disasters can happen to anybody: The case of Korea. Environmental Impact Assessment Review, 57, 1-9.

Haddow, G., Bullock, J., \& Coppola, D. P. (2017). Introduction to emergency management. Butterworth-Heinemann.

Harrison, J. S., Freeman, R. E., \& Abreu, M. C. S. D. (2015). Stakeholder theory as an ethical approach to effective management: Applying the theory to multiple contexts. Revista Brasileira de gestão de negócios, 17(55), 858-869.

Haworth, B., \& Bruce, E. (2015). A review of volunteered geographic information for disaster management. Geography Compass, 9(5), 237-250.

Hazarika, N., Barman, D., Das, A. K., Sarma, A. K., \& Borah, S. B. (2018). Assessing and mapping flood hazard, vulnerability and risk in the Upper Brahmaputra River valley using stakeholders' knowledge and multicriteria evaluation (MCE). Journal of Flood Risk Management, 11, S700-S716.

Hwang, B. G., \& Ng, W. J. (2013). Project management knowledge and skills for green construction: Overcoming challenges. International Journal of Project Management, 31(2), 272-284.

Islam, R., \& Walkerden, G. (2015). How do links between households and NGOs promote disaster resilience and recovery?: A case study of linking social networks on the Bangladeshi coast. Natural Hazards, 78(3), 17071727.

Khan, M. R., \& Rahman, M. A. (2007). A partnership approach to disaster management in Bangladesh: a critical policy assessment. Natural Hazards, 41(2), 359-378.

Krüger, F., Bankoff, G., Cannon, T., Orlowski, B., \& Schipper, E. L. F. (Eds.). (2015). Cultures and disasters: understanding cultural framings in disaster risk reduction. Routledge.

Lachlan, K., Spence, P., \& Lin, X. (2017). Natural disasters, twitter, and stakeholder communication. Social Media and Crisis Communication, 296.

Li, C. M., Hwang, T., \& Lee, N. Y. (1994, May). Threshold-multisignature schemes where suspected forgery implies traceability of adversarial shareholders. In Workshop on the Theory and Application of Cryptographic Techniques (pp. 194-204). Springer Berlin Heidelberg.

Mal, S., Singh, R. B., Huggel, C., \& Grover, A. (2018). Introducing linkages between climate change, extreme events, and disaster risk reduction. In Climate Change, Extreme Events and Disaster Risk Reduction (pp. 1-14). Springer, Cham. 
Martel, J. C. (2016). Exploring the integration of energy efficiency and disaster management in public policies and programs. Energy Efficiency, 9(2), 533-543.

Mileski, J., Gharehgozli, A., Ghoram, L., \& Swaney, R. (2018). Cooperation in developing a disaster prevention and response plan for Arctic shipping. Marine Policy, 92, 131-137.

Moe, T. L., Gehbauer, F., Sentz, S. \& Mueller, M. (2007) Balanced Scorecard for Natural Disaster Management Projects. Disaster Prevention and Management, 16 (5),785-806.

Mojtahedi, M., \& Oo, B. L. (2017). Critical attributes for proactive engagement of stakeholders in disaster risk management. International journal of disaster risk reduction, 21, 35-43.

Mojtahedi, M., \& Oo, B. L. (2017). Critical attributes for proactive engagement of stakeholders in disaster risk management. International Journal of Disaster Risk Reduction, 21, 35-43.

Mojtahedi, S. M. H. \& Oo, B. L. (2014) Stakeholders' Approaches to Disaster Risk Reduction in Built Environment 23, Disaster Prevention and Management, 356-369.

Najib, A. F., Soon, N. K., Zainal, R., Ahmad, A. R., \& Hasaballah, A. H. A. (2018). Influential factors in construction industry of Yemen. In Proceedings of the 21st International Symposium on Advancement of Construction Management and Real Estate (pp. 927-943). Springer, Singapore.

O'Leary, M. (2004). The first 72 hours: A community approach to disaster preparedness. iUniverse.

Paton, D., \& Johnston, D. (2017). Disaster resilience: an integrated approach. Charles C Thomas Publisher.

Peek, L. A. \& Mileti, D. S. (2002) The history and future of disaster research, in Bechtel, R. B.\& Churchman, A (Eds.), Environmental psychology, John Wiley \& Sons, New York, NY,

PMI (2013): A Guide to the Project Management Body of Knowledge (PMBOK® Guide) - Fifth Edition. Project Management Institute.

Renaud, F. G., Sudmeier-Rieux, K., \& Estrella, M. (Eds.). (2013). The role of ecosystems in disaster risk reduction. United Nations University Press.

Reyers, B., Nel, J. L., O’Farrell, P. J., Sitas, N., \& Nel, D. C. (2015). Navigating complexity through knowledge coproduction: Mainstreaming ecosystem services into disaster risk reduction. Proceedings of the National Academy of Sciences, 201414374.

Šakić Trogrlić, R., Wright, G. B., Adeloye, A. J., Duncan, M. J., \& Mwale, F. (2018). Taking stock of communitybased flood risk management in Malawi: different stakeholders, different perspectives. Environmental Hazards, 17(2), 107-127.

Shaw, R. (Ed.). (2012). Community-based disaster risk reduction. Emerald Group Publishing.

Stoney, C., \& Winstanley, D. (2001). Stakeholding: confusion or utopia? Mapping the conceptual terrain. Journal of Management Studies, 38(5), 603-626

Twigg, J. (2015). Disaster risk reduction. Overseas Development Institute: London, UK. 
United Nations Development Programme (UNDP) (1992) An Overview of Disaster Management. Geneva: UNDPDMTP. UNISDR (2014) Progress and challenges in Disaster Risk Reduction: A contribution towards the development of policy indicators for the post-2015 framework on disaster risk reduction. UN.

Verbeke, A., \& Tung, V. (2013). The future of stakeholder management theory: A temporal perspective. Journal of Business Ethics, 112(3), 529-543.

Weiss, J. W. (2014). Business ethics: A stakeholder and issues management approach. Berrett-Koehler Publishers.

Wieringa, S., Daamen, W., Hoogendoorn, S., \& Gelder, V. (2016). Framework to mitigate risks of crowd disasters at mass events in public urban space. Transportation Research Board (TRB). 